\title{
Neonatal hypoglycaemia in Nepal 2. Availability of alternative fuels
} Anthony M de L Costello, Deb K Pal, Dharma S Manandhar, Sujan Rajbhandari,
John M Land, Navin Patel

\begin{abstract}
Aims-To study early neonatal metabolic adaptation in a hospital population of neonates in Nepal.

Methods-A cross sectional study was made of 578 neonates, 0 to 48 hours after birth, in the main maternity hospital in Kathmandu. The following clinical and nutritional variables were assessed: concentrations and age profiles of blood glucose, hydroxybutyrate, lactate, pyruvate, free fatty acids (FFA) and glycerol; associations between alternative fuel levels and hypoglycaemia; and regression of possible risk factors for ketone availability.
\end{abstract}

Results-Risk factors for impaired metabolic adaptation were common, especially low birthweight (32\%), feeding delays, and cold stress. Blood glucose and ketones rose with age, but important age effects were also found for risk factors like hypothermia, thyroid hormone activities, and feeding practices. Alternative fuel concentrations, except FFA, were significantly reduced in infants with moderate hypoglycaemia during the first 48 hours after birth. Unlike earlier studies, small for gestational age (SGA) infants had significantly higher hydroxybutyrate:glucose ratios which suggested counter regulatory ketogenesis. Hypoglycaemic infants were not hyperinsulinaemic. Regression analysis showed risk factors for impaired counter regulation which included male and large infants, hypothermia, and poorer infant thyroid function. SGA infants and those whose mothers had received no antenatal care had increased counter regulation.

Conclusions-Alternative fuels are important in the metabolic assessment of neonates, and they might provide effective cerebral metabolism even during moderate hypoglycaemia. Hypoglycaemic infants generally had lower concentrations of alternative fuels through either reduced availability or increased consumption. SGA and post term infants increased counter regulatory ketogenesis with early neonatal hypoglycaemia, but hypothermia, male gender, and low infant $\mathrm{T} 4$ were associated with impaired counter regulation after birth.

(Arch Dis Child Fetal Neonatal Ed 2000;82:F52-F58)

Keywords: hypoglycaemia; Nepal; nutrition
Acute hypoglycaemia may impair cerebral function, ultimately leading to cell death, but the full implications of a low blood glucose cannot be appreciated in neonates without assessing the availability of other cerebral metabolic fuels, including ketone bodies, lactate, pyruvate, glycerol and free fatty acids. ${ }^{12}$ An increase in cerebral blood flow may also compensate for a low glucose concentration. ${ }^{3}$

In a cross sectional study Hawdon et al observed that up to a week of age the mean blood glucose of breastfed term infants was lower than that of formula fed infants, but ketone body concentrations were significantly higher on days 2 and 3. ${ }^{1}$ By contrast, small for gestational age (SGA) infants have minimal fat and glycogen reserves as well as a reduced capacity for gluconeogenesis, and increased glucose utilisation. Hawdon and Ward Platt studied metabolic adaptation in 33 SGA infants longitudinally, and found a reduced ketogenic response compared with the data from appropriate for gestational age infants in their cross sectional study. ${ }^{4}$ However, only 22 of their infants were born at term, and most were receiving intensive feeding or intravenous fluids.

We have already shown that in Nepal, a developing country, the prevalence of hypoglycaemia among uncomplicated term neonates tested during the first 48 hours is much higher than in industrialised countries: $41 \%(95 \% \mathrm{CI}$ : 37-45) had mild (less than $2.6 \mathrm{mmol} / \mathrm{l}$ ) and $11 \%$ (CI: 9-14) had moderate hypoglycaemia (less than $2.0 \mathrm{mmol} / \mathrm{l}$ ), and that low birthweight, delays in feeding and postmaturity were among the important risk factors. ${ }^{56}$ We also showed that intrauterine growth retardation is common in Nepal; 32\% of term newborn infants in our hospital population were low birthweight (less than $2.5 \mathrm{~kg}$ ). The 1998 UNICEF State of the World's Children gives similar estimates of low birthweight prevalence for India (33\%) and Bangladesh (50\%), compared with only $7 \%$ for the United Kingdom.

This study aimed to measure age profiles of concentrations of "alternative fuel" metabolites in Nepalese neonates, a nutritionally compromised population, and to assess whether apparently healthy but hypoglycaemic infants and SGA infants exhibit metabolic compensation by mobilisation of alternative fuels. Factors affecting counter regulation were evaluated. It has also been suggested that hyperinsulinaemia may contribute to the pathogenesis of hypoglycaemia in SGA infants. ${ }^{8}$ We therefore looked for evidence of 


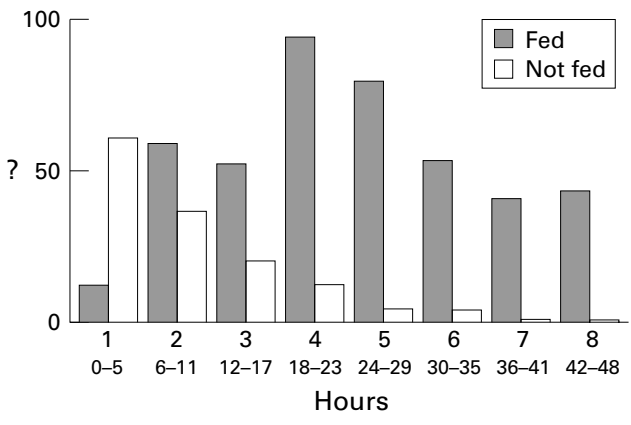

Figure 1 Onset of feeding by Nepalese neonates

hyperinsulinaemia in a subgroup of hypoglycaemic infants.

\section{Methods}

The details of the study population, sample size, selection of subjects, clinical history and examination of mothers and infants, data handling and analysis have been described before. ${ }^{6}$ A full verbal explanation of the study was given to the mother and her permission sought for enrolment. The study was approved by the hospital authorities and the Nepal Health Research Council.

Venous blood samples were collected from mothers and infants and divided: $400 \mu \mathrm{lmixed}$ with an equal amount of freshly prepared $6 \%$ perchloracetic acid (PCA); $400 \mu$ diluted with heparin; and 200-400 $\mu$ l stored as serum. Samples were put on ice and centrifuged at 3000 rpm for five minutes within 90 minutes of collection. Supernatant fluids were stored at $-20^{\circ} \mathrm{C}$ in liquid nitrogen until further analysis. Bedside maternal and infant haemoglobin measurements were made using a Hemocue microcuvette method.

Measurements of $\beta \mathrm{OH}$ butyrate, lactate, pyruvate and glycerol were made using a Cobas Fara centrifugal analyser and standard methods. Blood glucose was measured using the Roche Ultimate glucose oxidase method. Serum free fatty acids (FFA) were measured using a kit from Wako Chemicals Virginia, adapted for use on a Cobas Fara II analyser. Plasma free thyroxine (T4) and thyroid stimulating hormone (TSH) were measured using Vidas enzyme linked fluorescence assays according to the manufacturer's (BioMérieux) protocol.

The coefficient of variation and limit of detection for each assay were as follows: $\beta \mathrm{OH}$ butyrate $3.6 \%$ and $4 \mu \mathrm{mol} / 1$, pyruvate $2.1 \%$ and
$5 \mu \mathrm{mol} / \mathrm{l}$, FFA $6.5 \%$ and $0.05 \mathrm{mmol} / \mathrm{l}$, lactate $3.2 \%$ and $0.05 \mathrm{mmol} / 1$, glycerol $4.9 \%$ and 20 $\mu \mathrm{mol} / \mathrm{l}$, and for glucose, thyroxine, and TSH, as described in the previous paper. ${ }^{6}$ Values lower than the limits of detection of the assay were recorded as half the limit value, which allowed all variables to be log transformed if necessary.

Plasma samples from a subsample of infants ( $n=100)$ were analysed for insulin values using the Abbott IMx microparticle enzyme immunoassay. The limit of detection was $0.1 \mathrm{mU} / \mathrm{ml}$. This assay was chosen because there is no cross reactivity with proinsulin, concentrations of which are known to be high in the neonatal period. $^{9}$

\section{DATA ANALYSIS}

Values lower than the limits of detection of the assay were recorded as half the detection limit value, which allowed variables to be $\log$ transformed if necessary.

Two questions concerning the counter regulatory response to hypoglycaemia were posed for regression analysis using the log of the hydroxybutyrate:glucose ratio as the dependent variable. For both questions an important confounder entered into regression was the age at sampling. First, do thinner or lower birthweight infants counter regulate in response to hypoglycaemia differently than fatter or higher birthweight infants? To answer this question either birthweight or the log transformed ponderal index (PI) was entered as an independent variable, with age at sampling as a confounder.

Second, what are the risk factors for an impaired counter regulatory response to hypoglycaemia? Again, the log of the hydroxybutyrate:glucose ratio was entered as the dependent variable and potentially important maternal and infant independent variables (see below) were entered into a forward stepwise linear regression analysis; only those with $p$ values of less than 0.2 were included in the final model.

\section{Results}

CLINICAL AND NUTRITIONAL RISK FACTORS FOR METABOLIC VULNERABILITY AND PATTERN OF FEEDING

Potential clinical risk factors for metabolic vulnerability were highly prevalent in this population. Mothers were young (mean age 22 years), many $(53 \%)$ did not attend antenatal clinics, and $369(64 \%)$ were primigravidae. Over $80 \%$ of mothers came from poor households and

Table 1 Infant metabolic variables during first 48 hours

\begin{tabular}{|c|c|c|c|c|c|c|}
\hline \multirow[b]{2}{*}{ Variable } & \multicolumn{2}{|c|}{0 to 48 hours $(n=558)$} & \multicolumn{2}{|c|}{0 to 12 hours $(n=162)$} & \multicolumn{2}{|c|}{12 to 48 hours $(n=396)$} \\
\hline & $\begin{array}{l}\text { Geometric mean } \\
(S D)\end{array}$ & Min to $\max$ & $\begin{array}{l}\text { Geometric mean } \\
\text { (SD) }\end{array}$ & Min to $\max$ & $\begin{array}{l}\text { Geometric } \\
\text { mean }(S D)\end{array}$ & Min to $\max$ \\
\hline Blood glucose $(\mathrm{mmol} / \mathrm{l})$ & $2.69(1.47)$ & $0.1-5.8$ & $2.47(1.62)$ & $0.1-5.8$ & $2.79(1.39)$ & $0.1-5.7$ \\
\hline Hydroxybutyrate $(\mu \mathrm{mol} / \mathrm{l})$ & $110(3.5)$ & $2-1338$ & $41(3.5)$ & $2-379$ & $165(2.8)$ & $2-1338$ \\
\hline Lactate $(\mathrm{mmol} / \mathrm{l})$ & $2.40(1.50)$ & $0.3-12.7$ & $2.39(1.63)$ & $0.3-12.7$ & $2.4(1.45)$ & $0.7-7.14$ \\
\hline Pyruvate $(\mu \mathrm{mol} / \mathrm{l})$ & $136(1.5)$ & $14-322$ & $119(1.6)$ & $14-268$ & $144(1.4)$ & $43-322$ \\
\hline Glycerol $(\mu \mathrm{mol} / \mathrm{l})$ & $380(1.9)$ & $35-2313$ & $395(1.8)$ & $76-2313$ & $374(1.9)$ & $35-1620$ \\
\hline Free fatty acids (mmol/1) & $1.03(1.77)$ & $0.1-2.9$ & $1.07(1.98)$ & $0.1-2.87$ & $1.02(1.68)$ & $0.1-2.85$ \\
\hline $\mathrm{TSH}(\mathrm{mU} / \mathrm{l})$ & $19.3(2.0)$ & $1.4-170$ & $31.9(1.74)$ & $7.2-170$ & $15.7(1.9)$ & $1.4-55.6$ \\
\hline Free T4 $(\mathrm{pmol} / \mathrm{l})$ & $27.8(1.4)$ & $11-70$ & $21.1(1.32)$ & $11-46.4$ & $31.1(1.3)$ & $11.9-70$ \\
\hline Insulin & $\begin{array}{l}1.03(2.5) \\
(\mathrm{n}=99)\end{array}$ & $0.1-7$ & $\begin{array}{l}1.17(2.1) \\
(\mathrm{n}=30)\end{array}$ & $0.1-4.5$ & $\begin{array}{l}1.03(2.7) \\
(\mathrm{n}=69)\end{array}$ & $0.1-7$ \\
\hline
\end{tabular}


A

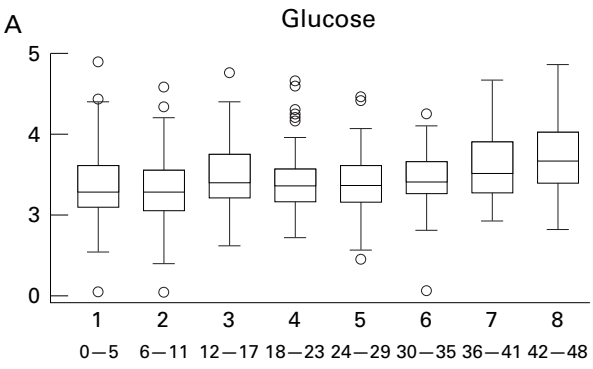

B

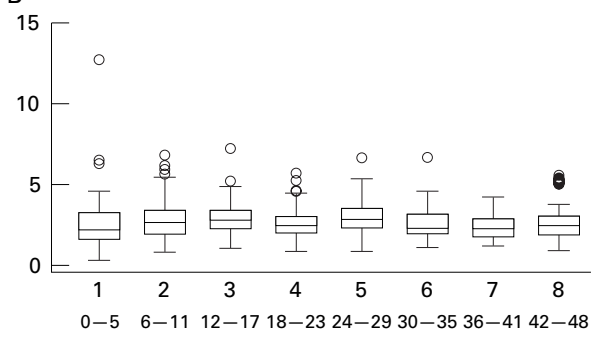

C

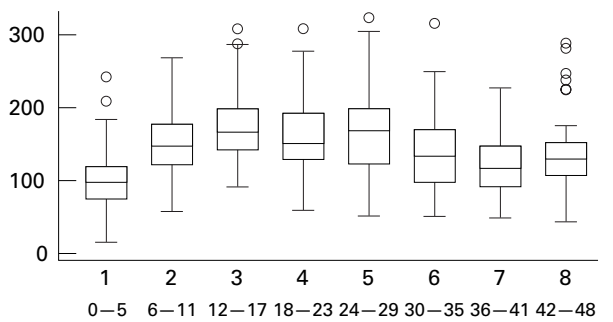

D

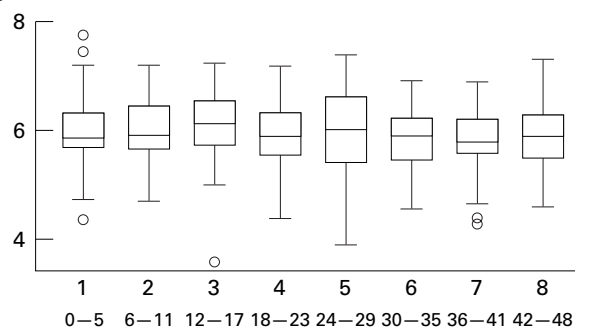

$\mathrm{E}$

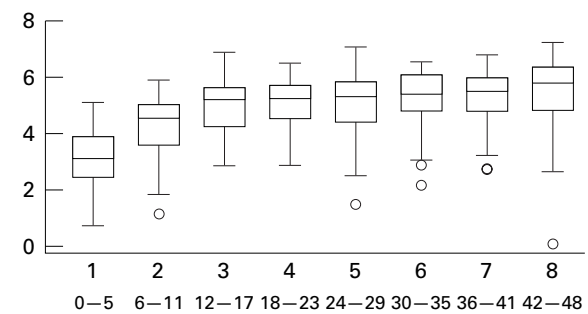

$\mathrm{F}$

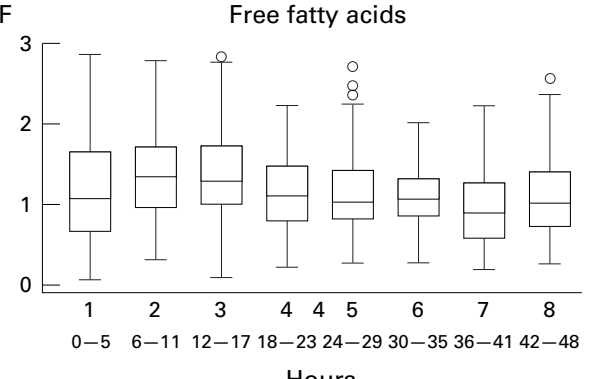

Hours used the "free" postnatal wards which levied only a small daily charge (about US $\$ 0.5$ ). As infants transferred for special care were excluded, only $4 \%$ of women with an assisted delivery were enrolled, and they were not analysed separately.

Maternal nutritional status was poor. The mean (SD) value for maternal height was 152.6 (6.1) $\mathrm{cm}$, for maternal weight was 49.4 (6.0) $\mathrm{kg}$, and for maternal haemoglobin 110 (21) g/l. The mean birthweight (2690 g) was lower than industrialised country norms, with $183(32 \%)$ of low birthweight (less than $2.5 \mathrm{~kg}$ ). All infants studied in the winter months $(n=300)$ were nursed in temperatures below the WHO recommended minimum level of $25^{\circ} \mathrm{C}$, whereas those infants enrolled in the summer $(n=278)$ were nursed in ambient temperatures above $25^{\circ} \mathrm{C}$.

Infant feeding patterns are important in the assessment of alternative fuels. One hundred and forty one $(24 \%)$ of the neonates had not been fed in the previous three hours (105 not at all), although this partly reflected their young age: $58 \%$ of infants under six hours of age and $37 \%$ from six to 12 hours were not fed (fig 1). Fed infants mostly (81\%) received breast milk. Only 10 babies received artificial milk or glucose, insufficient numbers to study separately. Although undoubtedly better than early feeding practices in rural areas, where most mothers deliver at home, a significant number of mothers in our hospital population had not fed their infants from 12 to 24 hours after birth.

METABOLIC PROFILES

Table 1 shows the overall geometric mean and geometric standard deviation values for metabolite values and fig 2 illustrates the change in metabolic profile with age in six hour bands from $0-48$ hours. The values of glycerol and $\beta$ hydroxybutyrate have been log transformed for ease of presentation. It is evident that infant pyruvate and hydroxybutyrate show a marked increase over the first 12 hours. There seems, however, to be less variation in lactate, glycerol, or FFA over the first 48 hours.

METABOLIC COMPENSATION DURING HYPOGLYCAEMIA?

Was there evidence for a compensatory rise in alternative fuels when glucose concentrations were low? Table 2 summarises the geometric mean concentrations of lactate, pyruvate, glycerol, $\beta$ hydroxybutyrate and FFA in groups according to blood glucose concentration above or below $2.0 \mathrm{mmol} / 1$. Except for FFA, all hypoglycaemic infants had significantly lower values of these alternative fuels. Blood lactate was lower in all age groups; blood pyruvate was lower from 0-40 hours; blood glycerol was lower from 0-30 hours; and blood hydroxybutyrate was lower from 0-24 hours in hypoglycaemic and non-hypoglycaemic infants. Free fatty acid values showed no consistent difference between hypoglycaemic and non-hypoglycaemic infants.

We also examined the evidence for a counter regulatory response to hypoglycaemia in SGA 
Table 2 Comparison of alternative fuel concentrations in infants with and without hypoglycaemia

\begin{tabular}{|c|c|c|c|c|}
\hline \multirow{2}{*}{$\begin{array}{l}\text { Fuel } \\
\text { Alternative fuel }\end{array}$} & \multicolumn{2}{|c|}{$\begin{array}{l}\text { Geometric mean fuel (and 95\% confidence } \\
\text { interval) }\end{array}$} & \multirow[t]{2}{*}{$\begin{array}{l}t \text { test for } \\
\text { difference }\end{array}$} & \multirow[t]{2}{*}{$p$ Value } \\
\hline & $\begin{array}{l}\text { Glucose }<2.0 \mathrm{mmol} / 1 \\
(\mathrm{n}=66)\end{array}$ & $\begin{array}{l}\text { Glucose } \leqslant 2.0 \mathrm{mmol} / 1 \\
(\mathrm{n}=492)\end{array}$ & & \\
\hline Lactate $(\mathrm{mmol} / \mathrm{l})$ & $2.01(1.76-2.29)$ & $2.46(2.38-2.54)$ & 3.86 & $<0.001$ \\
\hline Pyruvate $(\mu \mathrm{mol} / \mathrm{l})$ & $111(98-126)$ & $140(135-145)$ & 4.44 & $<0.001$ \\
\hline Glycerol $(\mu \mathrm{mol} / \mathrm{l})$ & $314(265-373)$ & $390(370-411)$ & 2.69 & 0.007 \\
\hline $\begin{array}{l}\text { Hydroxy-butyrate } \\
\qquad(\gamma \mathrm{mol} / \mathrm{l})\end{array}$ & $63(43-93)$ & $118(106-131)$ & 3.80 & $<0.001$ \\
\hline Free fatty acids $(\mathrm{mmol} / \mathrm{l})$ & $1.11(0.97-1.28)$ & $1.02(0.97-1.07)$ & -1.07 & 0.28 \\
\hline
\end{tabular}

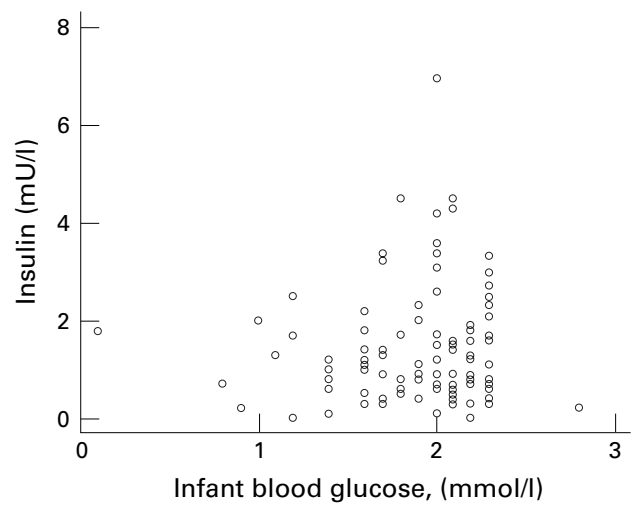

Figure 3 Insulin response to hypoglycaemia by neonates in Nepal $(n=99)$.

infants because an earlier study of 33 SGA infants (one third of whom were preterm and all of whom were receiving intravenous fluids or enteral feeding) suggested an impaired response during the first week. ${ }^{14}$ The geometric mean hydroxybutyrate:glucose ratio was significantly higher in low birthweight (50 [95\% CI 42-59])compared with infants with birthweight $2.5 \mathrm{~kg}$ and above $(38[33-43]), t$ test $\mathrm{p}=0.01)$. A linear regression was also performed using the log of hydroxybutyrate:glucose ratio as the dependent variable and entering firstly age at sampling as an important confounder, and then either birthweight or the $\log$ transformed ponderal index as an independent variable. In 555 infants for whom

Table 3 Stepwise multivariate linear regression using log hydroxybutyrate:glucose ratio as dependent variable

\begin{tabular}{|c|c|c|}
\hline Independent variable & Coefficient and $95 \%$ CI & $p$ Value \\
\hline $\begin{array}{l}\text { Age (hours) } \\
\text { Gestation }\end{array}$ & $1.02(1.00$ to 1.03$)$ & 0.002 \\
\hline $\begin{array}{l}\text { Post-term compared with } \\
\text { term }\end{array}$ & $1.94(1.37$ to 2.75$)$ & $<0.001$ \\
\hline Birthweight (kg) & $-1.57(-1.99$ to -1.23$)$ & $<0.001$ \\
\hline Rectal temperature $\left({ }^{\circ} \mathrm{C}\right)$ & $1.31(1.13$ to 1.51$)$ & $<0.001$ \\
\hline Maternal free T4 & $-1.04(-1.07$ to -1.01$)$ & 0.006 \\
\hline Infant free $\mathrm{T} 4$ & $1.02(1.01$ to 1.03$)$ & $<0.001$ \\
\hline Infant TSH (log values) & $-1.95(-3.03$ to -1.25$)$ & 0.003 \\
\hline Sex & $1.33(1.11$ to 1.60$)$ & 0.002 \\
\hline Female com & & \\
\hline $\begin{array}{l}\text { Antenatal care } \\
\text { Compared with none }\end{array}$ & $-1.24(-1.51$ to -1.01$)$ & 0.04 \\
\hline
\end{tabular}

The estimated effect on blood hydroxybutyrate/glucose ratio is the change in level for a unit increase in a continuous variable, or the stated categorical variable. The maternal and infant variables entered into the regression were maternal age, height, weight, haemoglobin, parity, social score, antenatal attendance and thyroid function; infant sex, birthweight, length, head circumference, haemoglobin, Apgar scores at one and five minutes, free T4 and TSH. Infant age at sampling was entered as an important potential confounder.

Number of observations $=515$

Geometric mean of hydroxybutyrate ratio $=41(\mathrm{~min} 0.2$ to $\max 135$ )

Adjusted R-squared $=0.25$ complete data were available, both birthweight ( $p$ 0.01) and ponderal index ( $p$ 0.003) showed a significant inverse relation after adjusting for age. This suggests that in the nutritionally compromised infants the ketogenic response to hypoglycaemia is increased.

\section{INSULIN VALUES}

In a subsample of 100 infants with low blood glucose concentrations (less than $2.4 \mathrm{mmol} / \mathrm{l}$ ), mean (SD) and range was 1.45 (1.18), $0-7, \mu \mathrm{U}$ per $\mathrm{ml}$. These values are appropriately low and do not indicate hyperinsulinaemia. Figure 3 shows the relation between infant insulin and blood glucose concentrations, indicating that the insulin response to hypoglycaemia was appropriate, and no evidence of inappropriate hyperinsulinaemia at low concentrations of blood glucose was found.

RISK FACTORS FOR A REDUCED COUNTER REGULATORY RESPONSE TO HYPOGLYCAEMIA Hydroxybutyrate is probably the most important ketone body for neonatal brain metabolism. What are the risk factors for an impaired counter regulatory response to hypoglycaemia? Again, the log of the hydroxybutyrate:glucose ratio was entered as the dependent variable and potentially important maternal and infant independent variables were entered into a forward stepwise linear regression analysis; only those with $\mathrm{p}$ values of less than 0.2 were included in the final model. The maternal variables entered into the regression were age, height, weight, haemoglobin, parity, social score, antenatal attendance and thyroid function; the infant variables included sex, birthweight, length, head circumference, haemoglobin, Apgar scores at one and five minutes, free T4 and TSH. Infant age at sampling was entered as an important potential confounder.

The final model is shown in table 3. The results showed that the hydroxybutyrate:glucose ratio (our measure of counter regulation) increased with age after birth in infants who were post term compared with those who were term; in infants with lower than higher birthweights; and in female compared with male infants. The hydroxybutyrate:glucose ratio was lower in infants who were hypothermic and whose mothers received antenatal care compared with those who did not. A better ratio was associated positively with better infant thyroid function values (higher T4, lower TSH), but negatively with maternal thyroid hormone activities.

\section{Discussion}

Much of the clinical significance of the blood glucose concentration rests on the availability to the brain of other metabolic fuels such as lactate, pyruvate, glycerol, $\beta$ hydroxybutyrate and FFA. Girard et al showed that ketogenesis occurs in the rat liver six to 12 hours after birth, and ketone bodies are used as oxidative fuels by various tissues during the suckling period. ${ }^{10}$

We have shown that alternative fuels, including hydroxybutyrate, rise sharply six to 12 hours after birth and our cross sectional data support Bougneres et al's dynamic turnover 
studies which showed active ketogenesis and quantitatively important ketone body fuel transport in human neonates. ${ }^{11}$

Are circulating levels of alternative fuels adequate for neonatal cerebral metabolism in Nepal? This is difficult to answer. Studies on circulating glucose, ketone bodies, and FFA concentrations in neonatal rats during the first 48 hours of birth have been summarised by Nehlig and Pereira de Vasconcelos. ${ }^{2}$ They compared glucose and hydroxybutyrate values in different studies: Krebs et al reported concentrations of $4.33 \mathrm{mmol} / 1$ and $150 \mu \mathrm{mol} / 1$ for rats on the first day ${ }^{12}$; Swiatek et al reported concentrations of $3.32 \mathrm{mmol} / \mathrm{l}$ and $240 \mu \mathrm{mol} / 1$ in malnourished rat pups (whose hydroxybutyrate concentrations were lower than in other studies during the later stages of the newborn period), ${ }^{13}$ and Girard et al reported $1.0 \mathrm{mmol} / 1$ and 175 $\mu \mathrm{mol} / 1$ taken at 16 hours of age, with much lower hydroxybutyrate concentrations in the first eight hours. ${ }^{14}$ These concentrations of hydroxybutyrate are not dissimilar to our measured values of 154 and $202 \mu \mathrm{mol} / 1$ in hypoglycaemic and normoglycaemic Nepali newborn infants, respectively, averaged over the first 48 hours, although great caution is needed when making comparisons across species.

The blood concentration is certainly important because uptake of ketone bodies by the brain is linearly related to the arterial concentration both in rats and neonates. ${ }^{15}{ }^{16}$ On the other hand, the neonatal infant brain seems to be able to take up and oxidise ketone bodies at rates much higher than those in older suckling and adult animals at a given arterial concentration, so lower concentrations may be quite adequate. ${ }^{16}$ Furthermore, neural cell types such as astrocytes possess ketogenic potential and might thus have a direct role in the provision of fatty acid derived ketone bodies during the suckling period. ${ }^{17}$ The vulnerability of neural cell types also varies. Oligodendrocytes, followed by microglia, are the most vulnerable glial cells to hypoxia or hypoglycemia in vitro, whereas astrocytes from the same preparations recover. ${ }^{18}$

Lactate is probably also important in the neonatal period. Immediately after birth and before the onset of suckling there is a time lapse during which glucose is scarce and ketone bodies are low owing to the delay in ketogenesis. Pellerin and colleagues have shown high expression of monocarboxylate transporter mRNAs in the neonatal mouse brain which supports a distinct role for lactate as an energy substrate in the neonatal compared with the adult brain. ${ }^{19}$ We found lactate concentrations of above $2 \mathrm{mmol} / 1$ in the first 12 hours of life which compares favourably with the figure of $1.95 \mathrm{mmol} / 1$ reported by Hawdon et al in the first 12 hours for vaginally delivered healthy term infants in Newcastle, UK. ${ }^{1}$

The role of FFA as an alternative fuel has not yet been clarified, nor whether they can cross the blood-brain barrier in the neonatal brain. Few cells (skeletal and cardiac muscle) have the ability to actually use FFA as an energy source. Glycerol is the only true gluconeogenic precursor (as opposed to lactate carbon being recycled to glucose), and its importance, there- fore, is that it has the potential to supplement glucose concentrations.

To answer the question about the adequacy of alternative fuel supplies definitively, it would be necessary to calculate cerebral influx and efflux of substrates, for which cerebral arteriovenous differences need to be combined with measurements of cerebral blood flow, a difficult task in neonates and rarely done in animal metabolic studies. We know that cerebral utilisation of ketone bodies is very active during the suckling period in rats, and that ketone bodies are metabolised by the brain as soon as they are taken up, so there are no intracellular pools. ${ }^{20}$

Do alternative fuel concentrations compensate for hypoglycaemia? We found that alternative fuels were lower in infants with lower blood glucose, except for FFA values. This does not, on first examination, support the proposition of compensatory availability in times of glucose shortage, but caution is needed. Another equally possible explanation is that concentrations of alternative fuels might be lower precisely because they are being actively consumed, an hypothesis which could be answered only by dynamic turnover studies. A compensatory increase in these other fuels might also become apparent over a longer time frame. Thirdly, it must be remembered that metabolic substrates gain entry into the brain by carrier mediated transport systems and therefore blood concentrations might not reflect the oxidative metabolic situation in the brain. None the less it is safest to assume that hypoglycaemic neonates are metabolically vulnerable and require monitoring and intervention below appropriate cutoff thresholds.

Do SGA infants have impaired ketogenesis? Our findings in Nepal suggest that those infants who were SGA and nutritionally compromised were more likely to have raised ketone values, which conflicts with the findings of Hawdon and colleagues, who studied a much smaller, mixed population of SGA term and preterm infants, who were also receiving intravenous or enteral feeding. Hawdon et al reported that "SGA term infants failed to mount a ketogenic response to low blood glucose concentrations," but none of the term SGA infants in their study had a blood glucose below $2.0 \mathrm{mmol} / \mathrm{l}$, and no significant differences between the SGA and AGA infants in the ketone body-glucose relation were reported. ${ }^{4}$ De Boissieu et al found that ketone turnover was lower in preterm infants in the first two weeks of life. ${ }^{21}$ Aynsley-Green and colleagues suggest that "both preterm and SGA infants are unable to generate counter regulatory ketogenesis as blood glucose concentrations fall," ${ }^{22}$ but this conclusion is based on the work by Hawdon et al. ${ }^{4}$ We did not study preterm infants.

Our data suggest, in contrast, that lower birthweight and thinner term infants in Nepal do show enhanced counter regulatory ketogenesis in the first two days of life once ketogenesis starts between six and 12 hours of age. Feeding practice differences between SGA and AGA infants might have played a small part in explaining our findings, although these did not emerge as a risk factor for poor counter regula- 
tion in the stepwise regression. Twenty seven per cent (105/393) of infants with a birthweight above $2.5 \mathrm{~kg}$ had not been fed in the previous three hours compared with only $19 \%$ $(35 / 148)$ of low birthweight infants (odds ratio 0.65 , CI: 0.42 to $1.0, p=0.05)$. On the other hand, we might reasonably conclude that healthy SGA infants do possess an adequate counter regulatory ketogenic response because we found a significant inverse relation between birthweight and hydroxybutyrate:glucose ratios even after controlling for age. The same inverse relation held for ponderal index as well.

Our measurement of appropriate insulin concentrations (using a highly specific enzyme immunoassay) in the presence of hypoglycaemia seems to refute the observation of Collins et $a l^{8}$ that hyperinsulinaemia may be common in growth retarded infants. Our findings support the conclusions of Hawdon and colleagues who, in a smaller study, also found no evidence of hyperinsulinaemia in SGA infants. $^{23} 24$ Older techniques for measuring insulin concentrations had marked crossreactivity with proinsulin and peptide C, concentrations of which are high in the newborn period and which might have explained their findings. Our findings contrast with studies in preterm infants which have shown an inability to switch off insulin secretion often for several weeks, ${ }^{21}$ thereby inhibiting the usual process of ketogenesis and gluconeogenesis.

We are not aware of any other studies that describe risk factors for counter regulation in human neonates. Our results showed that the hydroxybutyrate:glucose ratio (our measure of counter regulation) increased with age after birth, in infants who are post term compared with those who are term, in lower rather than higher birthweight infants, and in female rather than male infants. The hydroxybutyrate:glucose ratio was lower in infants who were hypothermic and whose mothers received antenatal care compared with those who did not. A better ratio was positively associated with better infant thyroid function values (higher T4, lower TSH), but negatively with maternal thyroid hormone concentrations.

The age effect was expected, and the gestational effect was small. The hypothermia effect was also expected in that hypothermia might either delay the onset of ketogenesis or increase cellular consumption. The relation with TSH values must be treated with caution because infant TSH falls dramatically after birth so an association may be artefactual, even though we log transformed TSH before entering it into the regression. The opposing effects of T4 status in mothers and infants are difficult to explain.

The gender association is intriguing: maybe boys have less mature enzyme systems, or differences in the hormonal regulation of ketogenesis. This warrants further investigation. The association between lack of antenatal care and higher infant hydroxybutyrate:glucose ratio cannot easily be explained. Mothers who did not receive antenatal care are more likely to be poor, and might have had clinical problems, or nutritional deficiencies, or been stressed, any of which might switch on the infant's counter regulatory response earlier.

In conclusion, our findings suggest that the circulating blood concentrations of alternative fuels in our population of healthy Nepalese infants, studied during the first two days of life, may well be sufficient for effective cerebral metabolism, even in these relatively nutritionally vulnerable infants. Lower concentrations of alternative fuels accompanied hypoglycaemia, and ketogenesis in response to a low blood glucose seem to be more pronounced in low birthweight and nutritionally compromised infants. None the less this was a cross sectional study and assessment of the absolute contribution of these fuels to metabolic adaptation will require dynamic turnover studies in high risk infants, using relatively non-invasive methods, to provide conclusive evidence of metabolic safety.

We thank Dr David Osrin for his advice.

This study was funded by a grant from the British Department for International Development.

1 Hawdon JM, Ward Platt MP, Aynsley-Green A. Patterns of metabolic adaptation for preterm and term infants in the first postnatal week. Arch Dis Child 1992;67:357-65.

2 Nehlig A, de Vasconcelos AP. Glucose and ketone body utilisation by the brain of neonatal rats. Progr Neurobiol 1993; 40:163-221.

3 Pryds O, Christensen NJ, Fris-Hansen B. Increased cerebral blood flow and plasma epinephrine in hypoglycemic preterm neonates. Pediatrics 1990;85:172-6.

4 Hawdon JP, Ward Platt MP. Metabolic adaptation in small for gestational age infants. Arch Dis Child 1993; 68:262-6.

5 Anderson S, Shakya KN, Shrestha LN, Costello AM. Hypoglycaemia: a common problem among uncomplicated newborn infants in Nepal. $f$ Trop Pediatr 1993;39:273-7.

6 Pal DK, Manandhar DS, Rajbhandari R, Land JM, Patel N, Costello AM de L. Neonatal hypoglycaemia in Nepal 1. Prevalence and risk factors. Arch Dis Child Fetal Neonatal Ed 2000;82:F46-51.

7 UNICEF. State of the World's Children. Oxford: Oxford University Press, 1998.

8 Collins JE, Leonard JV. Hyperinsulinism in asphyxiated and small-for-dates infants with hypoglycaemia. Lancet 1984;ii:311-13.

9 Hawdon JM, Hubbard M, Hales CN, Clark P The use of a specific radioimmunometric assay to determine preterm
neonatal insulin-glucose relationships. Arch Dis Child Fetal Neonatal Ed 1995;73: F166-F9.

10 Girard J, Duee PH, Ferre P, Pegorier JP, Escriva F, Decaux $\mathrm{JF}$. Fatty acid oxidation and ketogenesis during development. Reprod Nutr Dev 1985; 25(1B): 303-19.

11 Bougneres PF, Lemmel C, Ferre P, Bier DM. Ketone body transport in the human neonate and infant. $\mathcal{F}$ Clin Invest $1986 ; 77: 42-8$.

12 Krebs HA, Williamson DH, Bates MW, Page MA, Hawkins RA. The role of ketone bodies in caloric homeostasis. Adv Enzyme Regul 9:387-409.

13 Swiatek KR, Chao KL, Chao HL, Dombrowski GJ Jr. The utilisation of DL- $\left[3-{ }^{14} \mathrm{C}\right]$ hydroxybutyrate by malnourished rat pups. Neuroscience 1979;4:1751-60.

14 Girard J, Cuendet GS, Marliss EB, Kervran A, Rieutort M, Assan R. Fuels, hormones and liver metabolism at term and during the early postnatal period in the rat. 7 Clin Invest 1973;52: 3190-200.

15 Schroeder H, Bomont L, Nehlig A. Influence of early chronic phenobarbital treatment on cerebral arteriovenous differences of glucose and ketone bodies in the developing rat. Int f Dev Neurosci 1991; 9: 453-61.

16 Kraus H, Schlenker S, Schwedesky D. Developmental changes of cerebral ketone body utilization in human infants. Hoppe Seylers $Z$ Physiol Chem;355:164-70.

17 Cullingford TE, Dolphin CT, Bhakoo KK, Peuchen S, Canevari L, Clark JB. Molecular cloning of rat mitochondrial 3-hydroxy-3-methylglutaryl-CoA lyase and detection of the corresponding mRNA and of those encoding the remaining enzymes comprising the ketogenic 3-hydroxy3-methylglutaryl-CoA cycle in central nervous system of suckling rat. Biochem $\mathcal{f}$ 1998;329:373-81.

18 Lyons SA, Kettenmann H. Oligodendrocytes and microglia are selectively vulnerable to combined hypoxia and hypoglycemia injury in vitro. $f$ Cereb Blood Flow Metab 1998;18:521-30.

19 Pellerin L, Pellegri G, Martin JL, Magistretti PJ. Expression of monocarboxylate transporter mRNAs in mouse brain: Support for a distinct role of lactate as an energy substrate for the neonatal vs. adult brain Proc Natl Acad Sci USA for the neonatal 
20 Miller AL, Hawkins RA, Veech RL. The mitochondrial redox state of the brain. I Neurochem 1973; 20:1393-140. 21 De Boissieu D, Rocchiccioli F, Kalach N, Bougneres PF Ketone body turnover at term and in premature newborns in the first 2 weeks after birth. Biol Neonate 1995;67: 84-93. 22 Aynsley Green A, Hawdon JM, Deshpande S, Platt MW, Lindley K, Lucas A. Neonatal insulin secretion: implications for the programming of metabolic homeostasis. Acta Paediatr fpn 1997; 39 Suppl 1: S21-5.
23 Hawdon JM Aynsley-Green A, Alberti KGMM, Ward-Platt MP. The role of pancreatic insulin secretion in neonatal glucoregulation. 1. Healthy

24 Hawdon JM Aynsley-Green A, Bartlett K, Ward-Platt MP. The role of pancreatic insulin secretion in neonatal glucoregulation. 2. Infants with disordered blood glucose homeostasis. Arch Dis Child 1993;68:280-5.

\section{$\stackrel{3}{3}$ \\ क \\ Oо}

